Etnográfica

Revista do Centro em Rede de Investigação em

Antropologia

vol. $25(2) \mid 2021$

Vol. 25 (2)

\title{
Construindo o "bom trabalhador": inclusão de pessoas com deficiência no mercado de trabalho
}

Building the "good worker": inclusion of people with disabilities in the labour market

\section{Valéria Aydos}

\section{(2) OpenEdition}

\section{Journals}

Edição electrónica

URL: https://journals.openedition.org/etnografica/9818

DOI: 10.4000/etnografica.9818

ISSN: 2182-2891

\section{Editora}

Centro em Rede de Investigação em Antropologia

\section{Edição impressa}

Paginação: 289-314

ISSN: 0873-6561

\section{Refêrencia eletrónica}

Valéria Aydos, "Construindo o "bom trabalhador": inclusão de pessoas com deficiência no mercado de trabalho», Etnográfica [Online], vol. 25 (2) | 2021, posto online no dia 29 julho 2021, consultado o 19 janeiro 2022. URL: http://journals.openedition.org/etnografica/9818 ; DOI: https://doi.org/10.4000/ etnografica. 9818 


\section{Construindo o "bom trabalhador": inclusão de pessoas com deficiência no mercado de trabalho}

\section{Valéria Aydos}

Neste texto, analisamos os processos de inclusão das pessoas com deficiência no mercado de trabalho, tendo como foco uma análise curricular pedagógica e o cotidiano de interações entre professores e aprendizes de um curso de capacitação para pessoas com deficiência intelectual e/ou psicossocial. Vemos que, pensando nos modelos de "trabalhador ideal" exigidos pelo mercado, os esforços pedagógicos destes cursos acabam por "moldar" essas pessoas a um padrão considerado "mais aceitável”. Um dos efeitos desta ação está na responsabilização do indivíduo pelo sucesso ou fracasso de sua experiência, o que deixa em segundo plano a necessidade de adaptação das empresas às suas especificidades. Assim, chamamos a atenção para as moralidades e racionalidades - com relação à deficiência, classe social e geração - implícitas nestes cursos e, principalmente, para a necessidade de incorporação de uma perspectiva voltada para o modelo social da deficiência nos processos de inclusão como um todo.

PALAVRAS-CHAVE: deficiência, trabalho, políticas públicas, educação.

Building the "good worker": inclusion of people with disabilities in the labour market - In this paper, we analyse the processes of inclusion of people with disabilities in the labour market, focusing both on a pedagogical curricular analysis, and on the daily interaction between teachers and apprentices of a training course for people with intellectual and/or psychosocial disabilities. We argue that, thinking of the "ideal worker" models demanded by the labour market, the pedagogical efforts of these courses eventually "shape" these people to a standard considered "more acceptable". One of the effects of this action is on the blame of the individual for the success or failure of their experience, which leaves in the second place the need of adapting the companies to their specificities. Thus, we highlight the moralities and rationalities - related to the disability, social class and generation - that are implicit in these courses, and call the attention mainly to the need to incorporate a perspective focused on the social model of disability in the inclusion processes as a whole.

KEYWORDS: disability, work, public policies, education.

AYDOS, Valéria (valeria.aydos@gmail.com) — Programa de pós-graduação em Antropologia Social - Universidade Federal do Rio Grande do Sul, Brasil. 


\section{INTRODUÇÃO}

Olhar o corpo para além da perspectiva individual e biomédica, a qual vê no corpo da pessoa com deficiência apenas as suas lesões, possíveis faltas ou atrasos de desenvolvimento. Olhar a deficiência para além da sua materialidade física individual, mas entendê-la como relacional, como a experiência encarnada de uma corporalidade diferente que se dá na interação com a sociedade, no contexto social, cultural e econômico no qual existe. Vê-la como a experiência de um corpo que, assim como outros caracterizados por marcadores sociais da diferença humana (como raça e gênero), sofre os efeitos de barreiras que impedem a inclusão social de certas camadas da população. Esta é a perspectiva dos estudos da deficiência que inspira as análises aqui apresentadas.

O campo dos estudos da deficiência (disability studies), assim como outras áreas das ciências sociais, já há muitos anos tem chamado a atenção para o fato de que a visão biomédica da deficiência está calcada em um modelo que a individualiza e despolitiza, vendo-a como uma "tragédia pessoal". Tal visão capacitista, ${ }^{1}$ além de desqualificar e inferiorizar a pessoa com deficiência, impede o reconhecimento da deficiência como uma questão social.

Apesar da evidente hegemonia desta visão individualizada e desqualificadora dos corpos deficientes, o Brasil conta com uma ampla gama de leis e decretos, os quais exigem que organizações públicas e privadas garantam a inclusão social através da acessibilidade ${ }^{2}$ e a possibilidade de participação plena destas pessoas nos mais diversos espaços em nossa sociedade - direito universal previsto na Constituição Federal brasileira de 1988.

O Brasil, por exemplo, é um dos poucos países cuja Lei de Inclusão - Estatuto das Pessoas com Deficiência (Brasil 2015) - adquire status constitucional. Esta legislação incorpora em seus critérios classificatórios o que chamamos de modelo social da deficiência (Shakespeare 2006; Diniz 2012). Nesta perspectiva a deficiência não seria a lesão ou o "impedimento" em si, mas a lesão em interação com as barreiras sociais impostas a estas pessoas.

Promover a inclusão social das pessoas com deficiência, então, implica em possibilitar a acessibilidade destas pessoas nos mais diversos espaços da nossa sociedade, abolindo ao máximo as barreiras por elas encontradas neste processo. Especificamente com relação ao mercado de trabalho, temos a Lei n. ${ }^{\circ} 8213 / 91$, cujo texto especifica que empresas com mais de 100 funcionários tenham de 2 a 5\% de pessoas com deficiência em seu quadro laboral. A Lei de

I Para o conceito de capacitismo, ver os trabalhos de Anahí Guedes de Mello (2016).

2 Em conjunto com outros colegas antropólogas(os) e sociólogas(os) membros do Comitê Deficiência e Acessibilidade da ABA e da Anpocs, elaborei uma reflexão mais recente sobre acessibilidade em um material para eventos em espaços virtuais. Está disponível em $<$ https://www.anpocs2020.sinteseev entos.com.br/conteudo/view?ID_CONTEUDO=1031 > . 
Cotas, como é conhecida, apesar de datar de 1991, teve sua real efetivação, pelo menos no Rio Grande do Sul, ${ }^{3}$ somente a partir do final da década de 2000, com a implementação de uma fiscalização, por parte da Superintendência Regional do Trabalho (SRT), e de alguns projetos de inclusão criados no estado, como o Projeto Piloto de Incentivo à Aprendizagem de Pessoas com Deficiência no Rio Grande do Sul (2009), de iniciativa da própria SRT. Este momento de real efetivação das políticas de inclusão deve ser entendido, também, no bojo do Plano Viver Sem Limites, de 2014, de iniciativa do governo federal da época, o qual tinha como prerrogativa a construção de um novo modelo de desenvolvimento inclusivo para o país.

Neste contexto, os cursos de aprendizagem são vistos por agentes governamentais como um caminho para inclusão destas pessoas nas organizações empresariais. A partir, então, de ações de governo como o Projeto Piloto, as empresas começam a ser orientadas pela Superintendência Regional do Trabalho (SRT) ${ }^{4}$ a contratarem aprendizes através de cursos oferecidos pelo Sistema $S^{5}$ ou por outras instituições de ensino parceiras do projeto.

Nesse artigo buscamos analisar as ações de inclusão empreendidas através deste Projeto Piloto, centrando nossos esforços analíticos na compreensão dos sentidos e dos efeitos destes cursos na constituição de subjetividades consideradas "adequadas" para o mercado de trabalho, assim como na análise das resistências e das possibilidades de "agência" (Mahmood 2006) das pessoas com deficiência frente a estes processos de subjetivação e "pedagogização" para o trabalho empreendidos no curso. Pensamos nesses termos uma vez que o currículo de um curso pode visar à normalização das pessoas e seu enquadramento em um sistema vigente, bem como pode promover um empoderamento desse grupo fazendo com que a diferença seja valorizada e as pessoas se

3 O Rio Grande do Sul (RS) é uma das 27 unidades federativas do Brasil. Conta atualmente com mais de 11 milhões de habitantes (5,4\% da população brasileira) e está situado na região Sul do país, tendo por limites os estados de Santa Catarina e os países Argentina e Uruguai. Sua capital é o município de Porto Alegre, aonde esta etnografia foi realizada.

4 A relação da SRT com o Sistema S se deu por conta de uma parceria formada entre o Estado e as instituições para que a promoção da inclusão de pessoas com deficiência no mercado de trabalho se desse por meio dos cursos de aprendizado. Com o Projeto Piloto, a SRT, ao fiscalizar as empresas, ao invés de apenas multá-las pelo não cumprimento da lei, passa a oferecer a possibilidade deste tipo de ação conjunta de contratação de pessoas com deficiência.

5 Sistema S é o nome pelo qual ficou convencionado se chamar o conjunto de nove instituições de interesse de categorias profissionais, estabelecidas pela Constituição Brasileira. As receitas arrecadadas pelas contribuições ao Sistema S são repassadas a entidades, na maior parte de direito privado, que devem aplicá-las conforme previsto na respectiva lei de instituição. As entidades de aprendizado em questão são as seguintes: Serviço Nacional de Aprendizagem Rural (Senar); Serviço Nacional de Aprendizagem Comercial (Senac); Serviço Nacional de Aprendizagem em Cooperativismo (Sescoop); Serviço Nacional de Aprendizagem Industrial (Senai) e Serviço Nacional de Aprendizagem do Transporte (Senat). 
fortaleçam enquanto agentes de mudança das políticas. ${ }^{6}$ Enquanto um currículo normalizador vê a pessoa com deficiência como alguém "inapto" que precisa se tornar "apto" para o trabalho, um currículo que trabalhe na perspectiva social da deficiência prevê a participação social desses indivíduos respeitando as suas diferenças.

Entendemos, então, os cursos de aprendizado como espaços privilegiados de "cidadanização" (Ong 2003), nos quais "técnicas de viver são prescritas, a partir de uma produção mediada de valores, para que sujeitos aprendam a se autogovernarem". Procuramos, mais especificamente, analisar as concepções de deficiência e in/capacidade ${ }^{7}$ para o trabalho, assim como as racionalidades e moralidades que perpassam os saber-fazer de professores e psicólogos que neles atuam.

Para tanto, contamos com alguns dados obtidos através de uma etnografia realizada entre os anos de 2013 e 2016 , cujo trabalho de campo contou com 12 meses de acompanhamento da implementação do Projeto Piloto de Inclusão de Pessoas com Deficiência pela Aprendizagem no Rio Grande do Sul. Observamos diariamente, durante seis meses, as aulas do turno da manhã de um curso de aprendizagem do Sistema $\mathrm{S}$, e também por seis meses (duas vezes por semana) o cotidiano laboral de Tomás, ${ }^{8}$ um dos aprendizes deste curso, diagnosticado com autismo, em uma das empresas participantes do projeto. Posteriormente às observações, registradas em diários de campo, realizamos a coleta de documentos relativos aos cursos, como o currículo e as informações disponibilizadas no site da instituição, e entrevistas e conversas informais com os professores do curso, com os gestores das instituições de ensino e com gerentes e colegas da empresa parceira.

O texto apresenta, a seguir, informações sobre como se deram as etapas de recrutamento e seleção das pessoas para o Projeto Piloto, visando problematizar as racionalidades e moralidades que permeiam o chamado "mercado de trabalho" no Brasil; e uma análise dos efeitos e das produções destas questões no cotidiano das aulas de uma turma de pessoas com deficiência em um curso de aprendizagem e da experiência de primeiro emprego de Tomás, principal interlocutor da pesquisa.

6 Agradeço imensamente à Bruna Rocha Silveira, amiga e parceira nos estudos sobre deficiência e doutora em Educação (UFRGS), pelas ricas contribuições com relação à reflexão sobre o papel e os efeitos dos currículos nos processos de formação e nas subjetividades das pessoas.

7 Para um debate mais aprofundado sobre as concepções de deficiência, ver os trabalhos de Marco Gavério (2017) e Pedro Lopes (2014).

8 Ao finalizarem as aulas do curso, escolhemos Tomás para acompanharmos uma experiência no cotidiano empresarial. Este jovem se tornou um dos principais interlocutores desta pesquisa. Para uma etnografia de toda sua trajetória ao longo de seu processo de inclusão pela política de cotas, ver Aydos (2016 e 2017). 
RECRUTAMENTO E SELEÇÃO:

AÇÕES DE GOVERNO E "PÚBLICO ALVO" DAS POLÍTICAS

Os cursos de formação do Sistema S oferecidos para pessoas com deficiência contam com capacitações para o trabalho, com duração de aproximadamente seis meses a um ano, oferecidas em espaços educacionais em diferentes cidades do Brasil, para pessoas de baixa renda. As aulas, de clima ameno e informal, e ministradas de modo afetivo por professores selecionados de acordo com suas áreas de atuação, contam com módulos básicos, como português e matemática, e módulos práticos, direcionados para cada setor. Também são oferecidos momentos de socialização para o "treino" de comunicação pessoal, como performances de entrevistas de emprego, atendimento ao público ou como comportar-se em situações diversas nas empresas.

Tais cursos do Sistema $\mathrm{S}$ de ensino têm como finalidade a efetivação da chamada Lei do Aprendiz (n. ${ }^{\circ}$ 10.097/00) - um dispositivo legal que estabelece que as empresas são obrigadas a investirem de 5\% a 15\% em aprendizado (Costa 2013). As vagas destinadas aos aprendizes nas empresas contavam, até o início do Projeto Piloto, com um público de jovens alfabetizados, matriculados na rede de ensino e com idade até 18 anos, "perfil" que se modifica a partir da implementação da Lei de Cotas para pessoas com deficiência.

Com o fim de viabilizar a contratação de pessoas com deficiência a partir do sistema de aprendizagem, várias ações de governo foram empreendidas para a adequação desta lei ao "perfil" destas pessoas. Resoluções e portarias governamentais foram implementadas para que as vagas de emprego permitissem que: (a) a idade para o contrato de aprendiz fosse ilimitada para pessoas com deficiência; (b) pessoas com deficiência pudessem participar de programas de aprendizado sem grau mínimo de escolaridade; e (c) as empresas, a contar do início do curso de aprendizagem, dispusessem de um prazo de dois anos para a capacitação e contratação destas pessoas com fim de adequarem-se à Lei de Cotas (Costa 2013).

A partir do Decreto n. ${ }^{\circ} 7617$ que institui a Lei n. ${ }^{\circ} 12.470 / 11$, os aprendizes têm garantido o benefício da progressão continuada (BPC) ${ }^{9}$ durante todo o período de aprendizagem (teórico e prático) e são também remunerados pela empresa com metade do salário mínimo por quatro horas de trabalho diárias, almoço e transporte. Caso não venham a ser efetivados após o estágio, ou seja, futuramente desligados da empresa, voltam a receber o benefício sem necessidade de nova perícia para avaliação da deficiência.

9 O benefício de prestação continuada (BPC) da Lei Orgânica da Assistência Social (LOAS) é a garantia de um salário mínimo mensal à pessoa com deficiência e ao idoso com 65 anos ou mais que comprovem não possuir meios de prover a própria manutenção (renda familiar menor do que um quarto do salário mínimo vigente). Em 2019 o texto inicial da Reforma da Previdência, do presidente Jair Bolsonaro, propôs a redução do valor do benefício, mas a proposta foi derrubada no Senado. 
O Sistema S promove vários cursos de aprendizagem para o trabalho nos quais são recebidas pessoas com deficiência. Alguns destes cursos contam com a permanência destas pessoas dentro das instituições de ensino durante todo o período de aprendizagem, realizando visitas periódicas dos aprendizes (semanais ou com menor frequência) à empresa contratante para eventos, palestras ou outra atividade proposta em seu espaço de trabalho. Outros são organizados de forma que os aprendizes tenham um período das atividades que mencionamos nas dependências das instituições de ensino (em geral seis meses) e um segundo momento de treinamento já na atividade para a qual estão se candidatando dentro das empresas (pelo mesmo espaço de tempo).

Com o início do Projeto Piloto, alguns destes cursos começam a abrigar especialmente pessoas diagnosticadas com deficiência intelectual, síndrome de Down, transtornos do humor e, após a Lei Berenice Piana, ${ }^{10}$ de 2012, um crescente número de pessoas com diagnóstico de autismo. ${ }^{11}$ Estas pessoas são, em geral, indicadas pelas escolas especiais ${ }^{12}$ da prefeitura de Porto Alegre (através da Secretaria Municipal de Educação) ou por assistentes sociais (nos Centros de Referência da Assistência Social) que atendem as famílias de pessoas beneficiárias do BPC. Elas passam por uma seleção prévia realizada do Sistema S, cujos profissionais especializados avaliam quem teria condições de ingressar no curso e futuramente ter sucesso na sua inserção no mercado de trabalho.

\section{A “TABELA CHA”: PERFIS DESEJADOS NO MERCADO DE TRABALHO}

Um dos aspectos a ser analisado para compreensão do que estes agentes estão entendendo por pessoas mais ou menos excluídas são as concepções que gestores de pessoas/recursos humanos têm sobre estas deficiências em específico, assim como sobre quais seriam as competências - conhecimentos, habilidades e atitudes - adequadas ou exigidas hoje pelo mercado de trabalho. A chamada "tabela CHA" é um instrumento de avaliação destas competências que permite

10 Berenice Piana é uma militante brasileira, coautora da Lei n. ${ }^{\circ}$ 12.764, sancionada em 28 de dezembro de 2012, que leva seu nome e institui a Política Nacional de Proteção dos Direitos da Pessoa com Transtornos do Espectro Autista.

Il Não há um motivo específico para que este fosse o público dos cursos analisados aqui. Outros cursos do Sistema S contam também com pessoas cegas, surdas ou com deficiência física. Mas acreditamos que o capacitismo tem um espaço explicativo importante. Ou seja, o ato de julgar a capacidade da pessoa a partir de sua deficiência acaba agindo na escolha de pessoas com deficiências específicas para determinadas vagas de emprego (pessoas cegas para telemarketing, surdas para espaços que possam causar danos à audição, como pistas de aeroportos).

12 As chamadas "escolas especiais" são instituições especializadas, destinadas a prestar atendimento a educandos com deficiência e/ou condutas típicas, nas quais são desenvolvidos e utilizados currículos adaptados, programas e procedimentos metodológicos diferenciados das chamadas "escolas regulares". 
aos gestores de empresas recrutarem pessoas com "perfis" compatíveis com os cargos e funções exercidos pelos seus funcionários de forma adequada às vagas oferecidas. Ter a competência adequada a uma função significaria ter conhecimento (saber o quê e saber porquê); habilidade (capacidade técnica, saber como) e atitude (querer fazer, identidade, determinação).

As pesquisadoras Godoy e Antonello (2009: 160), doutoras em educação e administração, respectivamente, e especializadas na formação de administradores de empresas, entendem como competência "o resultado da mobilização de recursos (conhecimentos, habilidades e atitudes) para atuar numa determinada circunstância, numa determinada situação, a fim de atingir um desempenho esperado". E continuam enfatizando quais seriam as competências exigidas hoje no mercado de trabalho:

"Esse conceito de competência, ao destacar, sobretudo, as condições da situação na qual será colocada em ação, acaba por valorizar a flexibilidade e a capacidade de adaptação, em detrimento das respostas mais padronizadas, ou seja, respostas usadas anteriormente em outras situações. [...] Trata-se da capacidade do indivíduo pensar e agir dentro de um ambiente particular, supondo a capacidade de aprender (formal e informalmente) e de se adaptar a diferentes situações, a partir da interação com outras pessoas em diferentes contextos, onde ele é responsável pela construção e consolidação de suas competências (autodesenvolvimento), tendo em vista o aperfeiçoamento de sua capacitação, podendo, dessa forma, adicionar valor às atividades da organização, a si próprio (auto-realização) (sic) e à sociedade" (Godoy e Antonello, 2009: 160; grifos nossos).

Programas de TV como o quadro do administrador Max Gehringuer ${ }^{13}$ no programa de televisão "Fantástico", vídeos da Internet de outros "gurus da administração", ${ }^{14}$ como Waldez Ludwig, e sites de administração de empresas com sessões de "autoajuda" para busca de empregos divulgam cotidianamente um conjunto de qualidades individuais que deveriam compor perfis desejados hoje no mercado de trabalho. Blogs como o Contratanet, ${ }^{15}$ por exemplo, indicam que

13 Max Gehriguer é um dos administradores de empresas brasileiro mais requisitados para palestras empresariais, tendo sido eleito um dos 10 top voices influencers de 2019 do LinkedIn Brasil. Seu programa na rádio CBN e no programa "Fantástico" da Rede Globo é um tipo de reality show de empreendedorismo e gestão de negócios.

14 O termo "guru" é uma categoria nativa, utilizada com um sentido irônico e pejorativo para designar autores de best-sellers sobre negócios e personagens do circuito palestras/shows (Barbosa 2002).

15 A Contratanet é uma rede integrada de portais de vagas para estágio e empregos do Brasil. Sua tecnologia conecta instituições de ensino, empresas, candidatos e portais parceiros, aproximando as vagas de emprego dos profissionais que procuram colocação no mercado de trabalho. Disponível em $<$ https://www.contratanet.com.br/ >. 
"Existe determinado perfil profissional que as empresas procuram e quem possui as características já sai na frente dos adversários. Não estamos falando de atributos comuns, como pró-atividade e dedicação. Esses pontos já são considerados básicos para qualquer profissional. Pensando nisso, reunimos no post de hoje várias competências que as empresas buscam em um profissional do século XXI. Falaremos da capacidade que um colaborador deve ter para gerar resultados, da importância de se identificar com os valores da empresa e de questões ligadas à inteligência emocional, ao trabalho em equipe e à autogestão do conhecimento" (Contratanet; acesso em setembro de 2017; grifos nossos).

Tais saberes indicam que as competências idealmente exigidas hoje não estão calcadas em conhecimentos, mas sim em habilidades e atitudes como pró-atividade, inteligência, agilidade, criatividade, assertividade e inteligência emocional, características de um “indivíduo liberal empreendedor de si” (Rose 2007; Collier e Ong 2005).

Apesar de os conteúdos da Internet mencionados anteriormente apontarem uma tendência do mercado de trabalho para uma flexibilização destas qualidades com relação a diferentes cargos e funções, os processos seletivos continuam sendo realizados a partir destes perfis profissionais preestabelecidos e generalizantes. Estas tecnologias de gestão, calcadas em valores liberais de igualdade e meritocracia e no ideal de uma "cultura organizacional homogênea", ${ }^{16}$ ainda são predominantes na prática das organizações empresariais brasileiras.

Uma das questões que trazemos para reflexão sobre a prática destes saberes administrativos é o fato de que estas competências exigidas são exatamente aquelas que, segundo especialistas médicos e psicopedagogos, ${ }^{17}$ seriam "deficitárias" em pessoas com deficiência intelectual ou com transtorno do espectro autista (TEA). Segundo Clara, psicopedagoga responsável pelo acompanhamento das turmas de aprendizado, as pessoas com deficiência intelectual teriam

“a capacidade cognitiva, funcional e/ou 'de contexto' comprometidas. $\mathrm{Na}$ capacidade cognitiva entra a inteligência, como condições de ter raciocínio lógico-matemático, capacidade de abstrair ou inferir, de uso e entendimento da linguagem [... $\mathrm{Na}$ funcionalidade se avalia a AVD, atividade de vida prática, como ter autonomia em alimentação, vestuário, locomoção e higiene.

16 Sobre a meritocracia e outros valores presentes na cultura administrativa que predomina nas empresas brasileiras, ver os trabalhos de Lívia Barbosa (1996a, 1996b, 2002).

17 Cabe mencionar que, pelo menos no Rio Grande do Sul, a corrente que possui maior visibilidade no atendimento a pessoas com autismo é a chamada behaviorista e/ou cognitivo-comportamental. Para uma breve discussão sobre os especialistas em autismo, ver Aydos (2017, 2019). 
E o que chamamos de contexto seria se a pessoa tem uma rede de apoio, se frequenta espaços de sociabilidade, se tem capacidade de conseguir interagir de maneira adequada na sociedade, em grupo."

Já o TEA abrange um leque bastante variável de características, mas os especialistas psi interlocutores desta pesquisa entram em consenso com a concepção legal descrita na Lei Berenice Piana, que tornou possível a inserção de pessoas com transtorno do espectro autista na lei de cotas, a qual considera uma:

“§ $1 .^{\circ}[\ldots]$ pessoa com transtorno do espectro autista aquela portadora de síndrome clínica caracterizada na forma dos seguintes incisos I ou II:

I - deficiência persistente e clinicamente significativa da comunicação e da interação sociais, manifestada por deficiência marcada de comunicação verbal e não verbal usada para interação social; ausência de reciprocidade social; falência em desenvolver e manter relações apropriadas ao seu nível de desenvolvimento;

II - padrões restritivos e repetitivos de comportamentos, interesses e atividades, manifestados por comportamentos motores ou verbais estereotipados ou por comportamentos sensoriais incomuns; excessiva aderência a rotinas e padrões de comportamento ritualizados; interesses restritos e fixos" (Brasil 2012).

Neste sentido, no momento em que as políticas de cotas propõem a inserção destas pessoas em particular no cotidiano laboral, estes saberes biomédicos/psicossociológicos são colocados em tensão com saberes administrativos e de gestão. Por um lado, as empresas se veem frente a um conjunto de tecnologias de recursos humanos que parecem não fazer sentido para a gestão destas populações; por outro, pouco conhecem sobre as tecnologias de outras áreas, como da educação inclusiva ou da psicopedagogia, que as ajudariam a revisitar suas ferramentas.

Dois gestores da empresa onde observamos o estágio de Tomás, um jovem com autismo, chamaram a atenção, por exemplo, para o fato de "os meninos ficarem parados depois que acabam as atividades" (no sentido de não terem pró-atividade para solicitarem mais trabalho) e comentaram que Tomás "não se enturmava, não conversava com ninguém", "no almoço ficava sozinho, sempre na mesma mesa". As atitudes de Tomás indicavam, segundo os gestores, pouca habilidade de interação social com os colegas, o que para eles "dificultava a permanência do aprendiz na empresa". Ou seja, para os gestores e o mercado de trabalho, Tomás teria de se "normalizar" para entrar no currículo da empresa. Nesse sentido, como demonstraremos a seguir, o curso de capacitação, assim como o mercado de trabalho, também se mostrou como "normalizante". Mercado esse que prevê a participação de pessoas com 
deficiência, no entanto parece exigir que as pessoas mudem para entrar no mercado e não que o mercado mude sua forma para a efetiva inclusão dessas pessoas.

No cotidiano da gestão da inclusão, também os especialistas psi e biomédicos sentem-se desafiados a dialogar com estes saberes administrativos ao serem chamados para nova tarefa de auxiliar na capacitação das pessoas com deficiência e na "adaptação" destas nas empresas. Nesta interação, psicólogos organizacionais também revisitam suas práticas de avaliação, tratamento e acompanhamento destas pessoas para um trabalho nas empresas. Em várias de nossas conversas, Clara chama a atenção, por exemplo, para o desafio que é trabalhar em um ambiente menos controlado e protegido do que a clínica ou as escolas especiais, e salienta que a forma como podemos avaliar as habilidades e treinar uma pessoa diagnosticada com TEA, por exemplo, é totalmente diferente da que gestores de recursos humanos estão acostumados:

"Se na empresa as pessoas estão acostumadas a detectarem os pontos fracos de um funcionário e trabalhar no aprimoramento destes pontos, nas pessoas com deficiência temos que detectar os pontos fortes e focar neles. Muitas vezes os pontos fracos não são possíveis de serem aprimorados pela própria condição da pessoa, da deficiência em si” [Clara, diário de campo, 03 de dezembro de 2014].

Estes saberes, que ora entram em diálogo, ora em tensões e disputas, permeiam o dia a dia da gestão destas populações tanto nos cursos de capacitação quanto nas organizações empresariais. $\mathrm{O}$ cotidiano de trabalho das pessoas com deficiência conta ainda com o convívio com colegas que carecem de informação sobre as suas especificidades e têm de lidar com o medo do "diferente" - barreiras apontadas por várias pessoas com quem conversamos como as mais difíceis de serem superadas com relação às pessoas com deficiência intelectual e com autismo.

Se fizermos uma pequena busca na Internet por vagas de emprego, poderemos perceber que o mínimo nível de instrução formal exigido para trabalhos manuais é o ensino fundamental (para candidatos a vagas de serviços gerais ou de diarista) e o ensino médio completo (para vagas no comércio e indústria em geral). Não importa se a pessoa será alocada no balcão de vendas, no depósito de roupas ou na esteira de produção, as novas teorias de gestão dizem que o mercado exige que o trabalhador seja capaz de operar em todos os setores da empresa, não tendo sua tarefa segmentada e restrita a uma única função. ${ }^{18}$ Sendo assim, se as práticas de recrutamento e seleção não levassem 
em conta a lógica da inclusão social de pessoas com deficiência, as pessoas que participaram dos cursos de aprendizado não seriam contratadas sequer para o serviço mais manual e repetitivo.

Frente a este cenário, que conhecimentos, habilidades e atitudes são propostos nos cursos de aprendizado das políticas de inclusão, e como são operacionalizados, para que os aprendizes tenham um bom desempenho na empresa? Que critérios são acionados para avaliação da possibilidade de inserção dessas pessoas com sucesso na empresa? O que esses saber-fazer dos professores do curso podem nos dizer sobre o que eles estão entendendo por capacidade, deficiência e trabalho? E, em última instância, no que estes cursos estão colaborando para a construção da hegemonia de um "paradigma da inclusão" no mercado de trabalho?

A análise destas categorias êmicas nos indica racionalidades e moralidades presentes na nossa sociedade que são importantes de serem problematizadas para a identificação das barreiras sociais que estas pessoas encontram em suas trajetórias como aprendizes e trabalhadoras. É tal tarefa que nos desafia na análise do curso do Sistema $S$, o qual fez parte da etnografia junto a um grupo de pessoas com o diagnóstico de "deficiência intelectual", que deu origem a este texto. ${ }^{19}$

\section{A INCLUSÃO PELA APRENDIZAGEM: UM TEMPO PARA ADAPTAÇÕES}

Como já mencionamos, ao longo de seis meses, acompanhamos as aulas da turma da manhã em um dos cursos de aprendizagem para pessoas com deficiência que fazem parte do Projeto Piloto de Incentivo à Inclusão no RS. Os seis homens e quatro mulheres entre 16 e 25 anos, que fizeram parte do curso de aprendizagem no Sistema S, entre eles Tomás, são provenientes das classes populares da zona norte de Porto Alegre. A maioria reside com algum membro da família e três deles em um abrigo da prefeitura. Diagnosticados por um médico da empresa contratante como tendo deficiência intelectual, alguns frequentam escolas regulares de ensino com currículos "de inclusão" (em turmas de ensino de jovens e adultos) e outros estudavam em escolas especiais da prefeitura. A maioria lê e escreve, mas grande parte se enquadra em níveis fundamentais de escolarização formal, não atingindo o exigido para um currículo aceito no mercado de trabalho. Suas histórias de vida, além de marcadas pelas barreiras enfrentadas pela discriminação a suas deficiências, são acrescidas, segundo os professores do curso, pelo descrédito em suas potencialidades, pelo "abandono das famílias" e por outras mazelas de sua condição social.

19 Os laudos médicos destas pessoas apresentam em sua maioria o diagnóstico de retardo mental (CID 10 F 70.0), mas alguns aprendizes “somavam” nesta avaliação médica deficiências psicossociais, como esquizofrenia, transtornos do humor e "transtorno do espectro autista". 
Na base curricular do curso, há módulos de comunicação e expressão, de computação e matemática básica, de informações básicas sobre processos produtivos e de desenvolvimento de algumas habilidades práticas que os preparem para atividades que podem lhes ser atribuídas no futuro trabalho. Segundo o material disponibilizado na plataforma do Sistema S, os cursos visam qualificar as pessoas com deficiência para "enfrentar as exigências das novas relações de emprego e trabalho, fundamentado no princípio do direito ao exercício da cidadania”. Para tanto, os cursos propõem currículos flexíveis e adaptados às necessidades de seus alunos.

No curso que observamos, apesar de vários conteúdos práticos relativos às futuras tarefas dos aprendizes nas empresas para aonde seriam direcionados estarem presentes em aula, o foco do aprendizado centrou-se, principalmente, no desenvolvimento do que se poderia chamar de "competências sociais", presentes pontualmente no módulo de Comunicação e Expressão, mas reforçado ao longo de todas as aulas.

Este aprendizado foi permeado pela prática de atividades lúdicas, como fazer arte de sucata, pintar e costurar almofadas, decorar a árvore de Natal e visitar o Papai Noel no shopping center. O ter uma convivência respeitosa com os colegas; o chegar no horário para as aulas; o prestar atenção quando o professor fala e sempre levantar o dedo para esclarecer uma dúvida ou pedir para ir ao banheiro; assim como o tom de voz gentil, suave e pausado dos professores, são práticas pedagógicas que, em um primeiro momento, remetiam a ensinamentos necessários à socialização de crianças nos primeiros anos da escola. Os murais na parede da sala (figuras l e 2), feitos em EVA colorido e adornados com borboletas e flores, indicando as "palavras sábias" a servir de modelo, os "combinados" com a turma e a escolha de "auxiliares do dia" reforçavam esta atmosfera infantil própria dos anos iniciais da educação básica, que, naquele contexto, era ressignificada constantemente em comparações com o mundo do trabalho, espaço onde também existem estas regras de conduta e murais com o destaque do funcionário do mês.

O que podemos perceber foi que os conteúdos ministrados nas aulas são muito conhecidos em outras escolas profissionalizantes para pessoas com deficiência intelectual como as APAES para jovens e adultos. Conteúdos que vão além do conhecimento teórico e técnico sobre o trabalho a ser desenvolvido e buscam focar no comportamento e nas atitudes dos aprendizes. Nesse sentido, nos parece que os cursos preparatórios para o mercado de trabalho apresentam forte herança dos ideais da educação especial. Tal influência faz com que, ao visarem a permanência dessas pessoas em um mercado de trabalho altamente competitivo, acabem por criar currículos normalizadores. Afirmamos isso sem um caráter de julgamento moral daqueles que reproduzem esses currículos, uma vez que, muitas vezes, esse se apresenta como único instrumento possível para entrada e permanência das pessoas com deficiência em um mercado que 
Figura 1 - Fotos da parede da sala de aula, com as regras de conduta no curso de aprendizado para o trabalho.

Fonte: Valéria Aydos.

Descrição da imagem: Foto da parede da sala de aula com quatro quadros, dois em laranja e dois em azul. À esquerda vemos um espaço escrito "auxiliar do dia", com dois nomes presos com alfinetes coloridos e uma foto de um aprendiz e a pro-

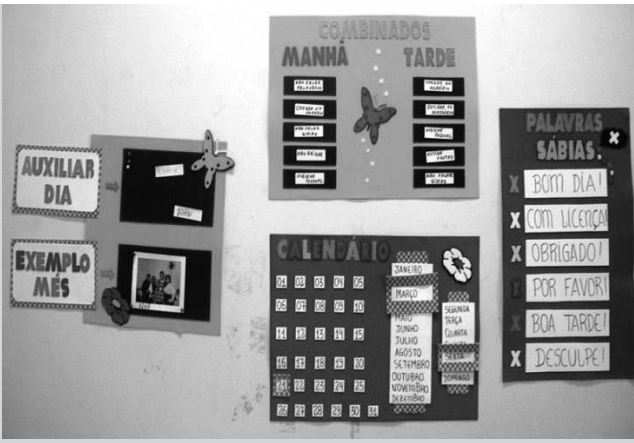
fessora no espaço destinado ao "exemplo do mês". Acima um quadro com os "combinados da turma", que serão descritos na figura 4, abaixo desta. Abaixo deste, um calendário no qual o mês e o dia são marcados, e à direita um último quadro com título "palavras sábias", listadas uma abaixo da outra, nesta ordem: bom dia, com licença, obrigado, por favor, boa tarde e desculpe".

Figura 2 - Detalhe do quadro "combinados da turma".

Fonte: Valéria Aydos.

Descrição da imagem: Aqui apresentamos o quadro com os "combinados da turma”, mencionado acima. Em duas colunas, uma para a turma da manhã e outra para os alunos da tarde, a imagem traz uma lista de atitudes a serem obedecidas pelos aprendizes. $\mathrm{Na}$ esquerda: não falar palavrões, chegar no horário, não falar gírias, não brigar e fazer a higiene

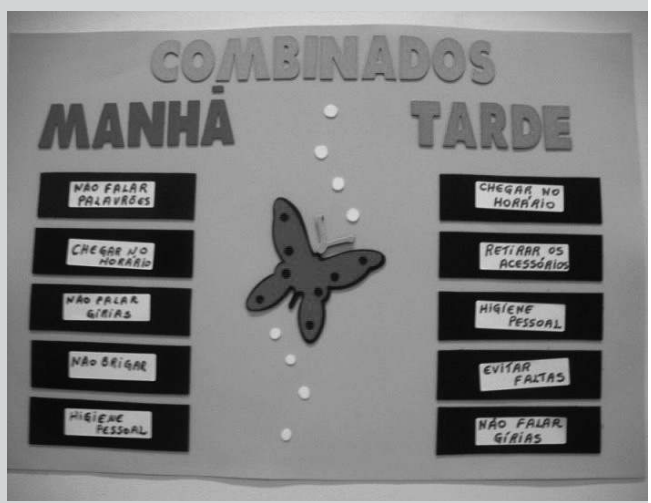
pessoal. Na direita: Chegar no horário, retirar acessórios, fazer a higiene pessoal, evitar faltas, não falar gírias. As das duas colunas são divididas por bolinhas amarelas e com a imagem de uma borboleta vermelha em EVA.

não pensa nas singularidades das pessoas, tenham elas deficiências ou não. No entanto, não podemos nos furtar de sugerir que acreditamos que uma maior reflexão sobre o fazer pedagógico informado pelo modelo social da deficiência possa trazer mudanças significativas na formação destes aprendizes e, consequentemente, efeitos importantes em seus processos de subjetivação e nas práticas de sua inclusão.

Aqui consideramos importante destacar os currículos não apenas como guias para que os professores e alunos sigam, mas como um formador identitário. Vemos o currículo, assim como Silva (1999), como um documento de identidade, uma vez que ele aponta uma trajetória, um percurso. Para o autor, "o currículo é relação de poder. O currículo é autobiografia, nossa vida, 
curriculum vitae: no currículo se forja nossa identidade. O currículo é texto, discurso, documento" (1999: 150). Assim, um currículo não está preocupado apenas com o que ensinar, mas o que as pessoas que estão inseridas nele devem ser. Um currículo está intimamente ligado ao que queremos que as pessoas se tornem.

No caso do curso aqui analisado, sem dúvida, queremos que os alunos se tornem pessoas aptas ao mercado de trabalho. E estar apto a esse mercado é estar apto ao seu currículo, que exige pessoas com inúmeras competências. O paradoxo envolvido nessa análise é que, em muitos casos, tornar apto ao mercado significa acabar com as singularidades dos sujeitos. Ao mesmo tempo em que se pensa no "resultado final" como a inclusão dessas pessoas no mercado, ao apagarmos suas singularidades, que são também suas "deficiências", acabamos por ver a inclusão como algo ambíguo: para incluir preciso ser igual; para ser igual tenho que deixar minha diferença de lado e, logo, ser diferente daquilo sou.

Para Silva (2000: 66), "se o currículo visar apenas o 'resultado final', sem as singularidades dos sujeitos envolvidos, fatalmente "fracassará'". Por outro lado, ao mesmo tempo em que o processo de normalização pareça violento, se isso não for feito, o sujeito com deficiência pode não conseguir ingressar no mercado e, assim, a inclusão não acontece em nenhuma instância. O paradoxo aqui presente é que a deficiência enquanto uma diferença "não pede tolerância, respeito ou boa vontade, mas desrespeitosamente, simplesmente difere" (Silva 2000: 66), o que torna a inclusão destas pessoas extremamente complicada. E é aqui, exatamente na prática cotidiana da inclusão, que mais se faz presente este paradoxo. Como podemos pensar estes cursos de modo que possamos ir além da armadilha do simples denuncismo das práticas pedagógicas normalizadoras e excludentes?

É evidente que, inicialmente, chamou-nos a atenção a infantilização que as técnicas de disciplinamento do curso impunham àquelas pessoas, já em torno dos 20 anos de idade. Perguntávamos: o que estas atividades lúdicas tinham a ver com o mundo do trabalho, afinal? Qual a finalidade deste curso? No entanto, ao longo das aulas fomos percebendo que existia ali uma problemática mais densa e complexa do que aparentava ser. Como citamos anteriormente, o currículo se mostra conectado com que tipo de pessoa é preciso que essas pessoas se tornem para entrar no mercado de trabalho.

Quando conversamos com alguns professores da instituição, nos disseram que esta turma da manhã era "mais complicada". Em resposta ao motivo deste juízo, explicaram que

"a deficiência intelectual é o de menos pra eles [...] Eles não têm casa, não tem uma família estruturada... Muitos moram em abrigos, pai alcóolatra, mãe que abandonou [...] Eles não tiveram um apoio quando pequenos, 
não têm nem os primeiros níveis de sociabilidade desenvolvidos" [Clara, diário de campo, dezembro de 2013].

Márcio, professor que permaneceu durante o tempo todo do curso, exemplificou a questão dizendo: "Eu tive que ensinar ao Gustavo que ele não podia cuspir no chão. Ele me disse: 'Ah, é? Não pode?', e eu ensinei que não, não pode. Que quando a gente quer cuspir a gente vai no banheiro...”.

Os comportamentos e as falas dos aprendizes do curso, na visão dos professores, evidenciam não apenas dificuldades cognitivas ou emocionais, mas ausência de aprendizados comportamentais que lhes teriam sido, na fala de uma professora do curso, "negligenciados na infância”. Mas, ao longo da pesquisa, fomos compreendendo que estes saberes, chamados de "socialização básica” pelos especialistas, tão óbvios para a grande maioria das pessoas daquela idade, eram um aprendizado novo para aquelas pessoas e, o que ficava evidente na preocupação dos professores, necessário para enfrentar os desafios que elas iriam ter pela frente no mercado de trabalho.

O fato de Gustavo realmente desconhecer que não podia cuspir no chão da sala de aula, ou as lembranças constantes dirigidas pelos professores à turma quanto à necessidade de tomar banho, pentear o cabelo, passar desodorante e escovar os dentes antes de vir para aula, colocava uma problemática que ia muito além de um "processo civilizatório" (Elias 1994) já tão evidenciado pelas ciências sociais em estudos sobre educação. Faz-nos refletir também sobre o porquê da chamada "socialização básica", na visão dos professores do curso, deva ser de responsabilidade somente da família. Estas fronteiras tão demarcadas entre o que é de responsabilidade das famílias e o que é dever do Estado traz em seu bojo um debate não apenas sobre o que significa ser "adulto", mas sobre o próprio conceito de cidadania, ${ }^{20}$ presente em nossos documentos legais e políticas públicas, como marcado por uma noção de "autonomia" atrelada à ideia de um indivíduo moderno "independente".

Os esforços dos professores em indicar e produzir valores e comportamentos aceitos no mundo do trabalho, que fariam com que aquelas pessoas não fossem demitidas por causa de uma "falta de habilidades sociais" dentro das empresas, tornavam-se ainda mais complexos quando eles tinham que traduzir estes ensinamentos para pessoas com deficiência intelectual e, mais ainda, para aquelas diagnosticadas também com deficiência psicossocial, como Gustavo, cuja trajetória de vida indica os desafios de inclusão destas pessoas: "Infelizmente ele não tem jeito. Se não tiver onde morar depois que completar a maioridade, terá que sair do abrigo e aí não se sabe o que vai ser dele", preocupava-se um professor ao ver que Gustavo continuava faltando às aulas. Naquela semana, 
Gustavo tinha sido internado por "haver surtado novamente". Na visão dos professores, para casos como o dele, diagnosticado também com esquizofrenia, os esforços de disciplinamento para melhor adaptação ao que viria a encontrar "no mundo lá fora" não pareciam ser o suficiente. Aqui vale pensarmos sobre qual o lugar da pessoa adulta, com deficiência mental, quando ela não consegue se adaptar aos limites impostos pela sociedade e não tem uma rede de apoio. Atualmente não existem políticas públicas para esses sujeitos que, muitas vezes, acabam nas ruas. Cabe perguntarmo-nos o que acontece com aqueles que "não tem jeito". Principalmente porque a maioria dos que "tem jeito" já são pessoas que, em geral, não contam com uma rede de apoio.

As preocupações dos professores com relação ao "curso dar certo" eram sempre permeadas pelo fato de a turma ser oriunda de classes populares. Neste caso, além de trazerem consigo uma experiência de deficiência que encontra barreiras de inclusão, têm uma trajetória de vida marcada pela sua condição social e, em alguns casos, por situações de abandono familiar. Esta dupla exclusão: a exclusão pela deficiência e pela sua condição social é verbalizada nas preocupações dos profissionais do curso com relação à turma específica desta pesquisa. Seus esforços evidenciavam a percepção de que "o mundo do trabalho lá fora" imporia barreiras à inclusão destas pessoas, por serem consideradas pelas empresas não apenas "imaturas emocionalmente" e "desqualificadas intelectualmente", mas também por terem comportamentos e estilos de vida "não adequados ao ambiente empresarial". Como efeito destas racionalidades de classe e biopolíticas (Rose 2007), diversas "técnicas de viver" (Ong 2003: 15) são prescritas nas aulas, para que os aprendizes aprendam a se portar no futuro emprego.

As práticas pedagógicas de aprendizado infantil, por um lado, e de repressão a certos comportamentos e vestimentas de jovens de classe popular, de outro, não raramente se sobrepunham e entravam em tensão ao longo do curso. Os "combinados" afixados na parede da sala de aula, como "não falar gírias", "retirar acessórios" ou "chegar no horário", eram as ponderações mais relacionadas ao "como se portar no trabalho" que evidenciavam este "perfil não desejado", como neste momento em que a professora ensinava como deveriam se comportar em uma festa da empresa:

“- Se tiver uma festa do trabalho, com o chefe de vocês lá, vocês vão dançar funk?, pergunta a professora.

[Silêncio na sala, indicando que este tipo de música era escutada por todos, mas imaginavam que a professora teria uma regra diferente]

- Então, vão dançar funk lá no meio, se rebolando tudo?

— Não né, Sôra!", Susan responde.

— Ah, bom... Não dá, né!?, concorda a professora.

- Mas todo mundo dança funk!, observa Walter. E se o chefe gostar de funk?, pergunta. 
[Reações de toda turma concordando com o colega]

—É, é mesmo! Então dá, né?!, pergunta outro aluno [risos de todos]

[A professora fica sem saber o que dizer e responde séria]

— Não, não dá." [Diário de campo, 14 de março de 2014].

A "ingenuidade", ou melhor, uma certa "curiosidade" sem "filtros sociais" com que os aprendizes interagiram na conversa evidencia não apenas que eles não compartilhavam da objeção à estética do funk (as calças caídas, os colares grossos de prata, o boné e o óculos apoiados atrás do pescoço), mas ilustra uma das formas particulares de resistência às restrições a comportamentos considerados impróprios ao mundo do trabalho pelos professores. Dentre estas moralidades, somavam-se outras não entendidas pelos professores na chave interpretativa da deficiência como, por exemplo, quando Lucas chegava "de olhos injetados" devido ao suposto consumo de maconha; ou quando Carlos dormia em aula por ter passado a noite anterior supostamente em claro na casa da namorada. Tais restrições (e as resistências a elas) marcam as barreiras sociais à inclusão social destas pessoas tanto ali, na sala de aula, quanto no cotidiano laboral que os esperaria.

No entanto, reduzir estas barreiras a uma estigmatização à forma de se vestirem ou à indolência considerada típica de adolescentes não reflete os desafios destes professores na tarefa de minimizar as suas dificuldades de inclusão social. As situações presenciadas ao longo do curso evidenciavam que a estas mazelas sociais somava-se uma sensação de que as categorias "infância" $\times$ "juventude" e "normalidade" $\times$ "deficiência" estavam sempre em tensão na forma como os professores lidavam com estes alunos e na própria constituição de suas subjetividades.

Em uma das aulas, quando os aprendizes se encaminhavam à visita ao Papai Noel, ao atravessarem uma avenida, instintivamente eu coloquei a mão em frente a Gustavo para protegê-lo de um carro em velocidade. Neste momento, ele prontamente reagiu perguntando irritado: "Tu acha que eu não sei atravessar a rua?". Tal situação - de evidência das categorias "idade" e "capacidade" também se fez presente, por exemplo, quando, em meio a situações de bagunça ou conversa demasiada em sala de aula, os professores chamavam a atenção dos aprendizes sem a adaptação de linguagem ou tom de voz doce, costumeiramente utilizados. Os estudantes, por sua vez, reagiam de tal forma acanhados e tristes que nossa percepção era a de que agiam "como se fossem crianças":

“Vocês já são bem grandinhos pra ficar de risinho e brincadeirinha, né?! Esses comportamentos não são aceitáveis na empresa. Vocês estão se preparando para o mercado de trabalho! São adultos, já!, diz a professora. [A turma abaixa a cabeça e Susan quase chora.]" [Diário de campo, 09 de dezembro de 2013]. 
Estes pontos de tensão se agravavam quando as justificativas do "infringir as regras" deparavam-se com a dúvida da justificação do erro apresentada pelos jovens, frente a situações de crítica. Eles, afinal, entendiam ou não as éticas e comportamentos indicados como corretos pelos professores? Como lidar com pessoas cronologicamente adolescentes, ou até adultas, que, nas concepções psicopedagógicas dos especialistas, e também na nossa percepção nas observações do curso, parecem "ser como crianças"? Eles podem ser responsabilizados pelos seus atos? Como prepará-los para estas situações no contexto do mundo do trabalho? Tal dificuldade, vivenciada na sala de aula pelos professores, fica evidente no caso de Walter, que assinou ele mesmo o nome da diretora do abrigo em que morava em um documento de autorização para a turma ir ao shopping center ver o Papai Noel:

"Quando cheguei a turma estava alvoroçada. Kátia veio logo me contar que hoje era o dia de ir no passeio. 'Vamos no shopping', menciona Carlos animado, 'ver o Papai Noel'. Mas Márcio [o professor] está preocupado. Olha as autorizações dos responsáveis, vai até Walter, lhe pergunta alguma coisa e sai da aula. Em seu retorno, visivelmente contrariado, diz:

- Gente, a gente tem uma situação muito chata aqui. Eu não sei se a gente vai poder ir no passeio. [Todos reagem contrariados]

- Como assim? Por quê?, perguntam.

- O Walter falsificou o documento de autorização do passeio.

[Na turma, reações de decepção, irritação e julgamento do colega... 'Ah, não acredito! Olha aí, Walter!']

— Eu não sabia que era um documento!, exclama Walter.

- Falsificar assinatura é crime. Se vocês fizerem isso no trabalho vão ser demitidos por justa causa... [E, se dando conta do termo jurídico, traduz:] Isso significa ser mandado embora e sair com vergonha...

- Mas eu não sabia que era crime... Não sabia que era documento, justifica Walter.

- Mas sabia que era errado, né, Walter?, diz o professor." [Diário de campo, 03 de dezembro de 2013].

Nestes momentos, voltava à cena a evidência de que estas pessoas "eram como crianças". Walter parecia realmente não ter consciência de sua infração. Mais do que isso, conhecendo melhor as trajetórias destas pessoas, nos damos conta de que suas histórias são marcadas, até a entrada nos cursos, pela limitação de espaços de sociabilidade e relações pessoais que os levassem a ter uma melhor desenvoltura em público. Foram muitos os relatos que escutamos, como este de Alison, hoje funcionário de uma indústria no estado do Rio Grande do Sul, que escreveu o que aprendeu em um dos cursos do Sistema S: 
Figura 3 - Relato de Alison, aprendiz contratado por uma indústria ${ }^{21}$. Fonte: Ministério Público do Trabalho no evento Autismo e Mercado de Trabalho.

Descrição da imagem: Fotografia da escrita de Alison. Seu texto, em letras maiúsculas, irregulares e com frases não alinhadas remete à

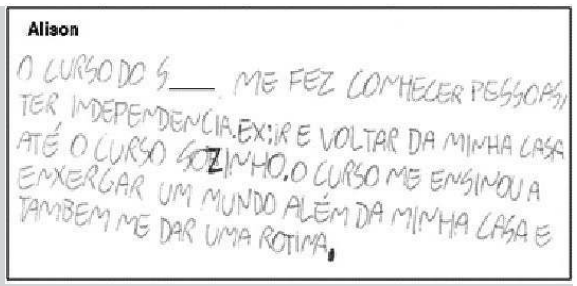
escrita de quem tem pouco treino nas letras.

$\mathrm{O}$ relato de Alison diz: "O curso do S... me fez conhecer pessoas, ter independência. Ex.: voltar da minha casa até o curso sozinho. O curso me ensinou a enxergar um mundo além da minha casa e também me dar uma rotina. Na palavra "sozinho" a letra $\mathrm{Z}$ está mais forte, corrigindo a escrita em $\mathrm{S}$ anterior.

A expressão escrita de Alison, apesar de provavelmente ter sido solicitada por algum profissional do curso, ilustra um pouco das narrativas de si destas pessoas, as quais, além de demonstrarem a importância e o espaço destes cursos em suas vidas, ressaltam uma subjetividade consciente de suas limitações. Em nossas conversas com Tomás durante os dois primeiros meses de estágio, foram repetidas as vezes em que ele se referiu a si mesmo e aos seus colegas como "pessoa que tem dificuldade".

O "não saber ler" ou "não conseguir fazer continha", nas palavras de Tomás, são marcadores que seguidamente os aprendizes mencionavam em aula como definidores de suas identidades, mas também como uma preocupação no sentido de questionarem se esta dificuldade seria importante ou não na hora de terem um trabalho, como nesta atividade de leitura de notícias de jornal no curso:

"Os alunos deveriam ler uma notícia, fazer um breve resumo, e ler seu resumo para os colegas. Patrícia fica parada e, ao ver seu desconforto, lembro que haviam me dito que ela não sabia ler. Todos estão folheando as revistas e jornais e Patrícia, depois de um tempo, levanta o dedo.

— Sim?, atende a professora.

- E quem tem dificuldade?, pergunta Patrícia.

- Quem tem dificuldade faz o quê, pessoal?, a professora devolve a pergunta pra turma.

— Pede ajuda, diz Gustavo, eu também tenho dificuldade.

['Eu também', 'eu também', observam os colegas. A professora concorda].

- Isso! Pede ajuda. E é sempre assim que a gente faz. No trabalho também. As atividades que vocês vão ter lá no trabalho vocês vão conseguir fazer e se não conseguirem, vão pedir ajuda pro chefe, tudo bem?!

21 Relato retirado da apresentação da representante do Ministério Público do Trabalho no evento Autismo e Mercado de Trabalho. Disponível em < https://www.trt4.jus.br/portais/trt4/modulos/noticias $/ 107570>$. 
[A professora vai até a mesa de Patrícia e diz]:

- Qual o filme que tu mais gosta?

- Barbie Butterfly, responde Patrícia.

— Então vai contar pra gente essa história, tá?" [Diário de campo, 14 de março de 2014].

Todos estes elementos nos levam a refletir sobre o fato de que os cursos de aprendizagem parecem dar conta de proporcionar uma capacitação para o trabalho que, mais do que o ensinamento de atividades laborais em si, possibilita um "tempo de adaptação" destas pessoas a um espaço de sociabilidade mais próximo do mundo das organizações empresariais. Neste sentido, a inclusão das pessoas com deficiência através do sistema de aprendizado ocupa um espaço privilegiado nas formas de gestão das políticas de inclusão. Como menciona a fiscal do trabalho em um evento comemorativo do projeto:

"A inclusão pelo aprendizado tem se demonstrado muito interessante... para as empresas porque têm mais tempo de conhecer as pessoas que vão contratar e por poderem contar com essa ajuda do Sistema S; e para as pessoas também porque podem se desenvolver com acompanhamento de profissionais que estão ali para auxiliá-los. Isso não podemos fazer dentro das empresas." [Diário de campo, 05 de junho de 2014].

O “desenvolver-se" para estar capacitado para o trabalho, então, implica muito mais um "disciplinamento" (Foucault 1997 [1985]) que possibilite a essas pessoas inserirem-se socialmente no mercado, um ambiente considerado pelos professores como sendo mais hostil que aquela sala de aula, do que o aprendizado de conhecimentos básicos (requeridos em currículos) ou atividades técnicas e manuais que viriam a realizar em seu cotidiano laboral.

Uma análise apressada destes cursos, apesar de válida, poderia nos levar a uma crítica ferrenha aos processos visivelmente "civilizatórios", à la Norbert Elias (1994), destas pessoas, cujo resultado seria uma "docilização dos corpos" (Foucault 1997 [1985]) frente a uma sociedade normatizadora, ou uma "higienização" de "gostos de classe" (Bourdieu 1997) estigmatizada no mercado de trabalho. Salientamos que a análise deste disciplinamento implica uma compreensão da complexidade da diversidade humana e do contexto no qual acontecem que não pode ser reduzida a estas críticas. Entender estes processos de inclusão em sua complexidade e em seus níveis mais microscópicos deve levar em conta não apenas a pouca eficácia de capacitação ou o não direcionamento dos conteúdos dos cursos, mas a análise das possíveis barreiras sociais que as pessoas com deficiência poderão enfrentar na real situação do mercado de trabalho no Brasil. E estas incluem as barreiras que as próprias empresas enfrentam ao empregarem estas pessoas, como, por exemplo, o não saberem de 
fato lidar com as manifestações das suas deficiências biofísicas e psicossociais reais, ou os preconceitos e resistências de seus funcionários e gestores.

Os aprendizes, dizem os professores do curso, para estarem aptos para o trabalho, devem saber que a empresa é um espaço hierárquico; de uso de uma linguagem formal e sem gírias; de exigência de vestimentas e higiene pessoal que não indiquem nem um comportamento infantil e nem um "gosto de classe fora do lugar". Entende-se, então, que os jovens indicados para contratação como "aprendizes com deficiência" pelo sistema de cotas devem passar por uma "socialização" antes de entrarem em uma empresa, mais do que pelo tempo de aprendizagem de alguma tarefa manual. Já a empresa que adere ao sistema de aprendizado também tem um tempo a mais para adaptar-se aos novos trabalhadores que chegam. Essa empresa deve saber que estará lidando com pessoas que poderão ter dificuldades de compreensão de ordens e tarefas; que poderão comportar-se ou entender as coisas "como crianças"; que podem ser mais sensíveis que o esperado dos adultos; que poderão ter dificuldades de comunicação e interação social e que podem sentir-se melhor em tarefas repetitivas do que criativas, e deve entender que todas estas qualidades são apenas facetas da diversidade humana e não demérito destas pessoas. No entanto, salientamos que uma questão central que se coloca aqui é: Quem deve se adequar? Quem deve moldar-se ao "outro"? Ou melhor, quem "consegue" realizar esta mudança?

\section{PARA QUE OS PREPARAMOS? O PARADOXO DO PARADIGMA DA INCLUSÃO NA PRÁTICA DA POLÍTICA}

O currículo e o curso aqui analisados tentam preparar o jovem com deficiência para um mercado de trabalho já de difícil adaptação a qualquer pessoa. Assim, para que essas pessoas se tornem aquilo que queremos que sejam, precisamos que as diferenças sejam, no mínimo, apaziguadas. Lembrando o pensamento de Sousa Santos (2003), que diz que as pessoas têm direito a serem iguais sempre que a diferença as tornar inferiores, contudo, têm também direito a serem diferentes sempre que a igualdade colocar em risco suas identidades, o que estamos fazendo com esses currículos em nome de uma possível inclusão? Um currículo tradicional, que visa fixar condutas, comportamentos e valores acaba por negar as diferenças e seu direito a elas, e aí entramos em um embate de resistência que poderia ser resolvido se pensarmos em diálogos entre as diferenças.

Pensamos ser importante dizer que inclusão não é apenas o processo de colocar as pessoas com deficiência no mesmo lugar que pessoas sem deficiência, mas permitir que pessoas com e sem deficiência participem, igualitariamente e com equidade das atividades sociais. Durante muitos anos em nossa história vivemos sob o paradigma da exclusão e segregação social das pessoas 
com deficiência; as pessoas com deficiência não tinham o direito de participar da vida social e, quando o tinham, era em espaços de segregação, como as escolas especiais. Estando segregadas, fadadas a conviverem apenas com outras pessoas com deficiência também, surgiram movimentos de empoderamento dentro desses espaços e a luta para que essas pessoas convivessem em outros lugares, com outras pessoas. Assim surgiram nas escolas, por exemplo, as classes especiais, o integracionismo.

Pensando nesses movimentos dentro de espaço escolar, na lógica da exclusão as pessoas com deficiência não tinham nem o direito de ter um lugar para estudar. Elas eram excluídas do processo educativo. Na lógica da segregação as pessoas com deficiência "ganharam" espaços para estudar, mas longe dos ambientes educativos considerados regulares. Na lógica da integração, classes especiais eram criadas dentro de escolas regulares, ou seja, pessoas com deficiência ganham um espaço perto, mas não a interação, o "estar junto". $\mathrm{Na}$ lógica da inclusão, pessoas com e sem deficiência estudam na mesma sala de aula de forma igualitária, com os mesmos direitos e de forma equitativa, ou seja, as especificidades da pessoa enquanto aluna, como o direito a uma pessoa de apoio, devem ser atendidas para que ela consiga permanecer no ambiente educacional.

Atualmente vemos essas quatro lógicas operando em nossa sociedade. Nos ambientes de trabalho também. Algumas empresas não cogitam a participação de pessoas com deficiência em seu quadro funcional, outras aceitam, mas em lugares separados, e em um último grupo de empresas, infelizmente ainda em minoria, pessoas com e sem deficiência trabalham juntas, tendo a diversidade como um valor.

Se pensarmos estas políticas a partir do "paradigma da inclusão" (Sassaki 1997, 2002), as empresas seriam o locus privilegiado de ação para efetivação da inclusão. São elas que irão receber as pessoas com deficiência. Para serem inclusivas, elas deveriam implementar novas ferramentas gerenciais e sensibilizar seus funcionários para convivência com a diversidade. As empresas devem capacitar funcionários e gestores, para que possam proporcionar condições ambientais e sociais adequadas à recepção destas pessoas, bem como funções compatíveis com suas reais competências e possibilidades de adaptação ao trabalho. No entanto, ao longo do curso, e também no cotidiano das empresas nas quais realizei observações, o que se percebe é uma responsabilização do indivíduo para que ele se adapte ao meio. Apesar do chamado "emprego apoiado" 22 ser um direito das pessoas com deficiência, ou seja, se necessitarem, elas devem ter seu trabalho acompanhado por uma pessoa responsável,

22 O emprego apoiado refere-se a um conjunto de procedimentos a serem adotados pelas empresas para a realização de uma "boa inclusão" destas pessoas no mercado de trabalho (Lobato 2009). Para uma discussão sobre cuidado e trabalho das pessoas com deficiência, ver Aydos e Fietz (2017). 
a solicitação de que elas sejam autônomas e independentes no seu cotidiano laboral, que não precisem do auxílio de ninguém para realizar as suas funções é uma constante. Em última instância, mesmo não sendo essa a intenção dos educadores, se o processo falhar, a pessoa sentirá que a responsabilidade pelo fracasso é sua.

Se entendermos a transformação destes sujeitos em "trabalhadores" como parte do processo de construção de sua cidadania, cabe perceber que a autonomia como centro de constituição do "sujeito cidadão" - aquele "sujeito empreendedor de si” (Rose 2007; Ortega 2009): independente, responsável e gestor dos próprios riscos - deve ser problematizada. Esta é uma forma de "governo de si" que demanda uma cidadania ativa e indivíduos capazes de monitorar e controlar a si mesmos.

Como bem chamaram a atenção as teóricas feministas da segunda geração do modelo social (Diniz 2012; Guimarães 2010), a eliminação das barreiras à inclusão nem sempre é o suficiente para a conquista de independência e autonomia. Algumas pessoas sempre irão depender de alguém ou de alguma coisa para terem autonomia. Neste sentido, torna-se fundamental que discutamos as relações de cuidado não apenas no espaço da casa, mas no espaço público, como o ambiente de trabalho. Este "apoio", nas palavras da assessora do projeto de inclusão, "é um direito das pessoas com deficiência e uma obrigação das empresas". Neste sentido, caberia refletir sobre a possibilidade de, em algum momento destes cursos, informar a estes futuros trabalhadores o seu direito de serem aceitos como são, em sua diversidade e especificidades, como um "direito de cidadania". Discutir o trabalho como um direito fundamental e esclarecer o que é "inclusão", paradigma tão comum nos currículos da educação, pode ser um caminho possível.

Conceber um currículo que contemple estas questões poderia "capacitar" estas pessoas de forma a propiciar-lhes ferramentas de barganha com a empresa que irá recebê-las. Será que saber os deveres das empresas para com eles não seria importante para construção de suas possibilidades de agência ao longo do seu processo de inclusão? Ainda, é importante pensarmos se um currículo que tenta moldar o sujeito com deficiência ao mercado de trabalho está promovendo inclusão ou está tentando excluir as diferenças para que o sujeito se torne cada vez mais parecido com o adequado, leia-se, sem deficiência? Ou seja, o currículo da empresa e dos cursos de capacitação está favorecendo a autoestima e autonomia dos sujeitos, ou propiciando maior submissão, separação e hierarquização? Esta reflexão não se pretende normativa. A ideia que queremos levantar é a de que, se a construção de cidadania é o objetivo final de todo este processo, cabe aqui refletir sobre que tipo de cidadania os agentes envolvidos nos projetos de inclusão querem e podem ajudar a construir, e qual é a cidadania possível para as pessoas com deficiência. Neste sentido, um caminho possível seria conhecer e também "capacitar" as empresas para 
este novo público, sensibilizando-as para o paradigma da inclusão e para a compreensão da deficiência na chave dos direitos humanos (Diniz, Barbosa e Santos 2010).

\section{BIBLIOGRAFIA}

AYDOS, Valéria, 2016, "Agência e subjetivação na gestão de pessoas com deficiência: a inclusão no mercado de trabalho de um jovem diagnosticado com autismo", Horizontes Antropologicos, 22 (46): 329-358. Disponível em < http://www.scielo.br/scielo.php?pid=S01 04-7 1832016000200329\&script=sci_abstract\&tlng=pt $>$ (última consulta em junho de 2021).

AYDOS, Valéria, 2017, Não É Só Cumprir Cotas: Uma Etnografia sobre Cidadania, Políticas Públicas e Autismo no Mercado de Trabalho. Porto Alegre: UFRGS, tese de doutorado em Antropologia Social.

AYDOS, Valéria, 2019, "A (des)construção do diagnóstico do autismo no contexto das políticas de cotas para pessoas com deficiência no Mercado de trabalho", Anuário Antropológico, 44 (1): 93-116.

AYDOS, Valéria, e Helena FIETZ, 2017, "When citizenship demands care: the inclusion of people with autism in the Brazilian labour market", Disability Studies Quarterly, 37 (4). Disponível em < http://dsq-sds.org/article/view/6087/4827 > (última consulta em junho de 2021).

BARBOSA, Lívia, 1996a, "Cultura administrativa: uma nova perspectiva das relações entre Antropologia e Administração", RAE - Revista de Administração de Empresas, São Paulo, 36 (4): 6-19.

BARBOSA, Lívia, 1996b, "Meritocracia à brasileira: o que é desempenho no Brasil?", Revista do Serviço Público, 120 (3): 58-102.

BARBOSA, Lívia, 2002, "Globalização e cultura de negócios", in Ana Maria Kirschner, Eduardo R. Gomes e Paola Cappellin (orgs.), Empresa, Empresários e Globalização. Rio de Janeiro: Relume Dumará, 21 1-225.

BOURDieU, Pierre, 1997, Razões Práticas: Sobre a Teoria da Ação. Campinas: Papirus Editora. BRASIL, 1991, Lei n. ${ }^{\circ} 8213$, de 24 de julho de 1991, "Dispõe sobre os planos de benefícios da Previdência Social e dá outras providências”. Disponível em < http://www.planalto.go v.br/ccivil_03/leis/18213cons.htm > (última consulta em junho de 2021).

BRASIL, 2012, Lei n. ${ }^{\circ} 12.764$, de 27 de dezembro de 2012, "Institui a política nacional de proteção dos direitos da pessoa com transtorno do espectro autista; e altera o § 3 do art. 98 da Lei n..$^{\circ} 8112$, de 11 de dezembro de 1990". Disponível em: < http://www.plan alto.gov.br/ccivil_03/_ato2011-2014/2012/lei/112764.htm > (última consulta em junho de 2021).

BRASIL, 2015, Lei n. ${ }^{\circ}$ 13.146, de julho de 2015, "Institui a lei brasileira de inclusão da pessoa com deficiência (estatuto da pessoa com deficiência)”. Disponível em: < http:// 
www.planalto.gov.br/ccivil_03/_ato2015-2018/2015/lei/113146.htm > (última consulta em junho de 2021).

CATTANI, Antônio, e Lorena HOLZMANN (orgs.), 201 1, Dicionário de Trabalho e Tecnologia. Porto Alegre: Zouk.

COLLIER, Stephen, e Aihwa ONG, 2005, "Global assemblages, anthropological problems", in Aihwa Ong e Stephen Collier, Global Assemblages: Technology Politics, and Ethics as Anthropological Problems. Oxford: Blackwell, 3-21.

COSTA, Ana Maria Machado da, 2013, “Inclusão gradual no trabalho: aprendizagem profissional”, in Liliana Passerino, Maria R. Bez, e Ana C. C. Pereira (orgs.), Comunicar para Incluir, Porto Alegre: CRBF, 1: 61-79.

DINIZ, Débora, 2012, O Que É Deficiência. São Paulo: Brasiliense.

DINIZ, Débora, Lívia BARBOSA, e Wederson SANTOS, 2010, "Deficiência, direitos humanos e justiça”, in Débora Diniz, e Wederson Santos (orgs.), Deficiência e Discriminação. Brasília: Letras Livres/UnB, 9-18.

ELIAS, Norbert, 1994, O Processo Civilizador. Rio de Janeiro: Jorge Zahar.

FOUCAUlt, Michel, 1997 [1985], Vigiar e Punir: História da Violência nas Prisões. Petrópolis: Vozes.

GAVÉRIO, Marco, 2017, "Nada sobre nós sem nossos corpos! O local do corpo deficiente nos Disability Studies", Revista Argumentos, 14 (1): 95-1 17.

GODOY, Arilda Schmidt, e Claudia Simone ANTONELlO, 2009, "Competências individuais adquiridas durante os anos de graduação de alunos do curso de Administração de Empresas", Revista de Ciências da Administração, 11 (23): 157-191. Disponível em $<$ https://periodicos.ufsc.br/index.php/adm/article/view/11347> (última consulta em junho de 2021).

GUIMARÃES, Raquel, 2010, "Gênero e deficiência: um estudo sobre relações de cuidado", in Débora Diniz e Wederson Santos (orgs.), Deficiência e Discriminação. Brasília: Letras Livres/UnB, 197-228.

LOBATO, Beatriz C., 2009, Pessoas com Deficiência no Mercado de Trabalho: Implicações da Lei de Cotas. São Carlos: UFSCar, dissertação de mestrado em Educação Especial.

LOPES, Pedro, 2014, "Debatendo deficiência: ser, estar, tornar-se? Questionamentos a respeito do uso de uma categoria”, apresentado na 29. ${ }^{a}$ Reunião Brasileira de Antropologia, Natal, 3 e 6 de agosto de 2014.

MAHMOOD, Saba, 2006, "Teoria feminista, agência e sujeito liberatório: algumas reflexões sobre o revivalismo islâmico no Egipto”, Etnográfica, 10 (1): 121-158. Disponível em $<$ https://doi.org/10.4000/etnografica.6431 > (última consulta em junho de 2021).

MELLO, Anahi Guedes de, 2016, "Deficiência, incapacidade e vulnerabilidade: do capacitismo ou a preeminência capacitista e biomédica do Comitê de Ética em Pesquisa da UFSC", Ciência e Saúde Coletiva, 1 (10): 3265-3276.

ONG, Aihwa, 2003, Buddha is Hiding: Refugees, Citzenship, the New America. Berkeley, Los Angeles e Londres: University of California Press.

ORTEGA, Francisco, 2009, "Neurociências, neurocultura e ajuda cerebral", Interface: Comunicação, Saúde, Educação, 13 (31): 247-260.

ROSE, Nikolas, 2007, The Politics of Life Itself: Biomedicine, Power and Subjectivity in the Twenty First Century. Princeton: Princeton University Press.

SASSAKI, Romeu Kazumi, 1997, Inclusão: Construindo Uma Sociedade para Todos. Rio de Janeiro: WVA. 
SASSAKI, Romeu Kazumi, 2002, “Terminologia sobre deficiência na era da inclusão”, Revista Nacional de Reabilitação, V (24): 6-9.

SILVA, Tomáz Tadeu da, 1999, Documentos de Identidade: Uma Introdução às Teorias do Currículo. Belo Horizonte: Autêntica.

SILVA, Tomáz Tadeu da, 2000, Alienígenas na Sala de Aula: Uma Introdução aos Estudos Culturais em Educação. Petrópolis: Vozes.

SHAKESPEARE, Tom, 2006, "The Social Model of Disability”, em Lennard Davis (org.), The Disability Studies Reader. Nova Iorque: Routledge, 194-204.

SOUSA SANTOS, Boaventura de, 2003, "Por uma concepção multicultural dos direitos humanos", Boaventura de Sousa Santos (org.), Reconhecer para Libertar: Os Caminhos do Cosmopolitismo Multicultural, Rio de Janeiro: Civilização Brasileira, 427-462.

Receção da versão original / Original version

$2019 / 02 / 15$

Aceitação / Accepted

$2019 / 11 / 29$

Pré-publicação online / Pre-published online

$2021 / 01 / 07$ 